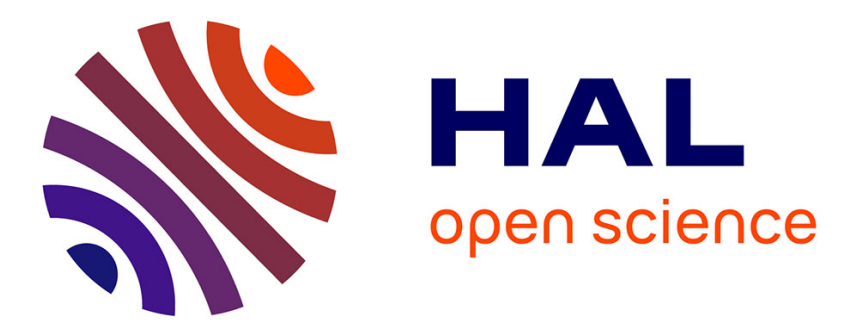

\title{
Valence state of cerium in the hexagonal CeM5 compounds with the transition metals
}

D. Gignoux, F. Givord, R. Lemaire, H. Launois, F. Sayetat

\section{To cite this version:}

D. Gignoux, F. Givord, R. Lemaire, H. Launois, F. Sayetat. Valence state of cerium in the hexagonal CeM5 compounds with the transition metals. Journal de Physique, 1982, 43 (1), pp.173-180. 10.1051/jphys:01982004301017300 . jpa-00209375

\section{HAL Id: jpa-00209375 https://hal.science/jpa-00209375}

Submitted on 1 Jan 1982

HAL is a multi-disciplinary open access archive for the deposit and dissemination of scientific research documents, whether they are published or not. The documents may come from teaching and research institutions in France or abroad, or from public or private research centers.
L'archive ouverte pluridisciplinaire HAL, est destinée au dépôt et à la diffusion de documents scientifiques de niveau recherche, publiés ou non, émanant des établissements d'enseignement et de recherche français ou étrangers, des laboratoires publics ou privés. 


\title{
Valence state of cerium in the hexagonal $\mathrm{CeM}_{5}$ compounds with the transition metals
}

\author{
D. Gignoux, F. Givord, R. Lemaire \\ Laboratoire Louis-Néel (*), C.N.R.S., 166X, 38042 Grenoble Cedex, France
}

H. Launois

C.N.E.T., 106, rue de Paris, 92220 Bagneux, France

and F. Sayetat

Laboratoire de Cristallographie (*), C.N.R.S., 166X, 38042 Grenoble Cedex, France

(Reçu le 13 mai 1981, révisé le 4 septembre, accepté le 18 septembre 1981)

\begin{abstract}
Résumé. - Nous avons étudié l'état de valence du cérium dans $\mathrm{CeCo}_{5}, \mathrm{CeNi}_{5}, \mathrm{CeCu}_{5}$ et les composés pseudobinaires $\mathrm{Ce}\left(\mathrm{Ni}_{1-x} \mathrm{Cu}_{x}\right)_{5}$ à l'aide de mesures des paramètres de maille, des propriétés magnétiques et de l'étude de l'absorption des rayons $\mathrm{X}$. Alors que les paramètres de maille de $\mathrm{CeCu}_{5}$ correspondent à l'état de valence $\mathrm{Ce}^{3+}$, les expériences d'absorption de rayons $\mathrm{X}$ montrent que dans $\mathrm{CeCo}_{5}$ et $\mathrm{CeNi}_{5}$, le cérium est dans le même état de valence, proche de $4+$, comme dans l'oxyde isolant $\mathrm{CeO}_{2}$. Les écarts à la stoechiométrie dans les composés $\mathrm{RCo}_{5}$ $(\mathrm{R}=$ terre rare) rendent compte des différences dans les anomalies du paramètre $a$ des composés du Ce dans les séries $\mathrm{RCo}_{5}$ et $\mathrm{RNi}_{5}$. Dans $\mathrm{Ce}\left(\mathrm{Ni}_{0,1} \mathrm{Cu}_{0,9}\right)_{5}$, Ce est dans l'état $3+$ et la variation thermique de sa susceptibilité est caractéristique des effets du champ cristallin sur l'ion $\mathrm{Ce}^{3+}$. Au contraire, la susceptibilité de $\mathrm{CeNi}_{5}$ est d'un ordre de grandeur inférieure et pratiquement isotrope; comme dans $\mathrm{YNi}_{5}$, elle provient essentiellement des électrons $3 \mathrm{~d}$ $\mathrm{du} \mathrm{Ni}$, qui sont très proches de l'apparition du ferromagnétisme. Dans les composés $\mathrm{Ce}\left(\mathrm{Ni}_{1-x} \mathrm{Cu}_{x}\right)_{5}$, le changement de valence du Ce est linéaire jusqu'à $x=0,3$ et devient plus rapide pour les plus fortes concentrations. Nous discutons l'évolution de l'état de valence du Ce à partir de la structure de bande des différents composés, en particulier de la position du niveau de Fermi et de l'état $4 \mathrm{f}^{1}$.
\end{abstract}

\begin{abstract}
The valence state of cerium in $\mathrm{CeCo}_{5}, \mathrm{CeNi}_{5}, \mathrm{CeCu}_{5}$ and the pseudo-binary $\mathrm{Ce}\left(\mathrm{Ni}_{1-x} \mathrm{Cu}_{x}\right)_{5}$ compounds has been studied by means of measurements of lattice parameters, magnetic properties and X-ray absorption. Whereas the lattice parameters of $\mathrm{CeCu}_{5}$ correspond to $\mathrm{Ce}^{3+}$ valence state, $\mathrm{X}$-ray absorption experiments show that, in $\mathrm{CeCo}_{5}$ and $\mathrm{CeNi}_{5}$, Ce has the same valence state, close to $4+$, as in the insulator $\mathrm{CeO}_{2}$. Stoichiometry deviations in the $\mathrm{RCo}_{5}$ compounds ( $\mathrm{R}=$ rare earth) can be correlated with the difference in the anomalies of the $a$ lattice parameter of $\mathrm{Ce}$ compounds in the $\mathrm{RCo}_{5}$ and $\mathrm{RNi}_{5}$ series. In $\mathrm{Ce}\left(\mathrm{Ni}_{0.1} \mathrm{Cu}_{0.9}\right)_{5}, \mathrm{Ce}$ is in the $3+$ state and the thermal variation of the susceptibility is characteristic of crystal field effects in the $\mathrm{Ce}^{3+}$ ion. In contrast the susceptibility of $\mathrm{CeNi}_{5}$ is one order of magnitude smaller and almost isotropic; as in $\mathrm{YNi}_{5}$, it arises mainly from the $\mathrm{Ni} 3 \mathrm{~d}$ electrons which are close to the onset of ferromagnetism. In the $\mathrm{Ce}\left(\mathrm{Ni}_{1-x} \mathrm{Cu}_{x}\right)_{5}$ compounds, the Ce valence state decreases linearly with $x$ up to $x=0.3$ and more rapidly for higher copper concentrations. The evolution of the $\mathrm{Ce}$ valence state is discussed in terms of the band structure of the different compounds, especially the relative position of the Fermi level and the $4 f^{1}$ state.
\end{abstract}

1. Introduction. - The $\mathrm{RM}_{5}$ compounds (with $\mathrm{R}=$ rare earth and $\mathrm{M}=\mathrm{Co}, \mathrm{Ni}, \mathrm{Cu})$ crystallize in the hexagonal $\mathrm{CaCu}_{5}$-type structure $(\mathrm{P} 6 / \mathrm{mmm})$ where $\mathrm{M}$ atoms occupy two different sites : $2 \propto\left(\frac{1}{3}, \frac{2}{3}, 0 ; \frac{2}{3}, \frac{1}{3}, 0\right)$ and $3 g\left(\frac{1}{2}, 0, \frac{1}{2} ; 0, \frac{1}{2}, \frac{1}{2} ; \frac{1}{2}, \frac{1}{2}, \frac{1}{2}\right)$, while $R$ atoms lie in

(*) Laboratoires propres du C.N.R.S., associés à l'Université Scientifique et Médicale de Grenoble.
$1 \mathrm{a}(0,0,0)$. In such a close packed stacking of two different spherical atoms, the $a$ cell parameter is directly related to the $R$ and $M$ atomic radii by $a=\sqrt{3}\left(r_{\mathrm{R}}+r_{\mathrm{M}}\right)$; the $c$ parameter depends almost entirely on the $\mathrm{M}$ atomic radius :

$$
c=\sqrt{15 r_{M}\left(r_{M}-2 r_{R} / 15\right)-r_{R}^{2}} .
$$


In the $\mathrm{RCu}_{5}$ series, the $a$ parameter follows the lanthanide contraction : $\mathrm{Ce}$ is consequently trivalent in $\mathrm{CeCu}_{5}$. In $\mathrm{CeNi}_{5}$ and $\mathrm{CeCo}_{5}$ an abnormal reduction of the $a$ parameter is observed which must be associated with a $\mathrm{Ce}$ valence higher than 3 [1]. In $\mathrm{CeCo}_{5}$ a tetravalent state for $\mathrm{Ce}$ has been deduced from the comparison of its spontaneous magnetization $\left(5.5 \mu_{\mathrm{B}} / \mathrm{CeCo}_{5}\right)$ with that of other ferromagnetic compounds : $\mathrm{YCo}_{5}\left(7.5 \mu_{\mathrm{B}}\right), \mathrm{LaCo}_{5}\left(7.1 \mu_{\mathrm{B}}\right)$ and $\mathrm{ThCo}_{5}\left(4.8 \mu_{\mathrm{B}}\right)$ [2], in which thorium is tetravalent. A neutron diffraction study has confirmed that cerium is not magnetic in $\mathrm{CeCo}_{5}$ [3]. The $\mathrm{CeNi}_{5}$ compound is paramagnetic at any temperature. Its susceptibility shows a broad maximum around $100 \mathrm{~K}$. Its thermal variation has been interpreted by Buschow et al. [4] as resulting from a progressive change from a $4+$ valence state of cerium at $0 \mathrm{~K}$ to an intermediate valence state at room temperature, due to thermal excitation to the $3+$ magnetic state. More recently, K. R. Bauchspiess et al. [5] have observed a similar double peaked edge of the $\mathrm{L}_{\mathrm{III}} \mathrm{X}$-ray absorption of $\mathrm{Ce}$ in $\mathrm{CeNi}_{5}$ and the insulator $\mathrm{CeO}_{2}$. Assuming that the absorption edge associated to an integral valence must always be single, they have deduced an intermediate valence close to 3.3 for these two compounds.

In the present study, the valence state of cerium in the $\mathrm{CeM}_{5}$ compound is analysed from measurements of lattice parameters, magnetic properties and X-ray absorption. The $\mathrm{Ce}$ change of valence in the pseudobinary $\mathrm{Ce}\left(\mathrm{Ni}_{1-x} \mathrm{Cu}_{x}\right)_{5}$ system is also studied.

The alloy constituents were $99.9 \%$ pure metals. The polycrystalline samples were melted by induction in a cold crucible. The $\mathrm{CeNi}_{5}$ single crystal was prepared by the Czochralsky method.

2. Crystallographic properties. - The change of the lattice parameters with the $\mathrm{Cu}$ concentration $x$ has been studied in the $\mathrm{Ce}\left(\mathrm{Ni}_{1-x} \mathrm{Cu}_{x}\right)_{5}$ compounds and for comparison in the similar $\mathrm{La}, \mathrm{Pr}$ and $\mathrm{Nd}$ alloys. For $0 \leqslant x \leqslant 0.9$ all the alloys were obtained in a single phase, and no miscibility gap was observed whatever the heat treatment employed. Figure 1 shows that the $a$ and $c$ parameters decrease as the $\mathrm{Cu}$ concentration $x$ decreases from $\mathrm{CeCu}_{5}$ to $\mathrm{CeNi}_{5}$. For the $\mathrm{La}$, $\mathrm{Pr}$ and $\mathrm{Nd}$ alloys, the same monotonic variation is followed, as expected with rare earth $3+$ ions. In the Ce alloys, the same dependence is observed only down to $x=0.8$. The Ce is then in the $3+$ state for $0.8 \leqslant x \leqslant 1$. Below $x=0.8$, there occurs a deviation of the $a$ parameter followed by a drastic decrease around $x=0.4$. The deviation $\Delta a$ from the $3+$ type variation (Fig. $1 a$, dashed line) is shown in figure $2 a$. A deviation of the $c$ parameter is also found but it is much less pronounced. Around $x=0.4$ the $c$ parameter variation shows an inflection tangent wwith a very weak slope (Fig. 1b). As shown in the introduction, the $c$ parameter is less dependent on the rare earth radius $r_{R}$ than is the $a$ parameter.

Such irregular variations of the lattice parameters
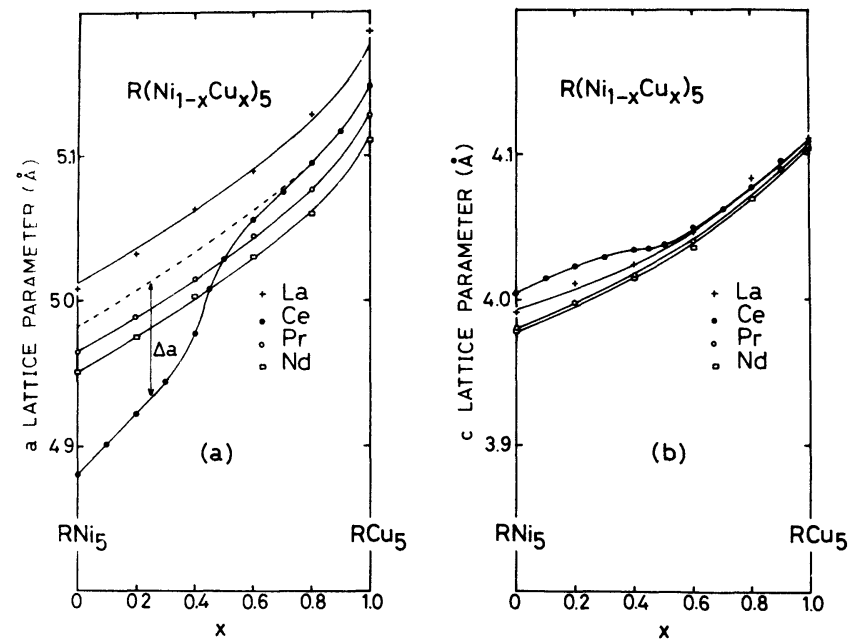

Fig. 1. - Lattice parameter variation versus the $\mathrm{Cu}$ concentration $x$ in the $\mathrm{R}\left(\mathrm{Ni}_{1-x} \mathrm{Cu}_{x}\right)_{5}$ compounds for $\mathrm{R}=\mathrm{La}, \mathrm{Ce}, \mathrm{Pr}$ and $\mathrm{Nd}$. a) $a$ lattice parameter. The dashed line corresponds to a variation of the $\mathrm{Ce}$ compound identical to the $\mathrm{La}, \mathrm{Pr}$ and $\mathrm{Nd}$ ones. $b$ ) $c$ lattice parameter. Values for $x=1.0$ are taken from reference [1].

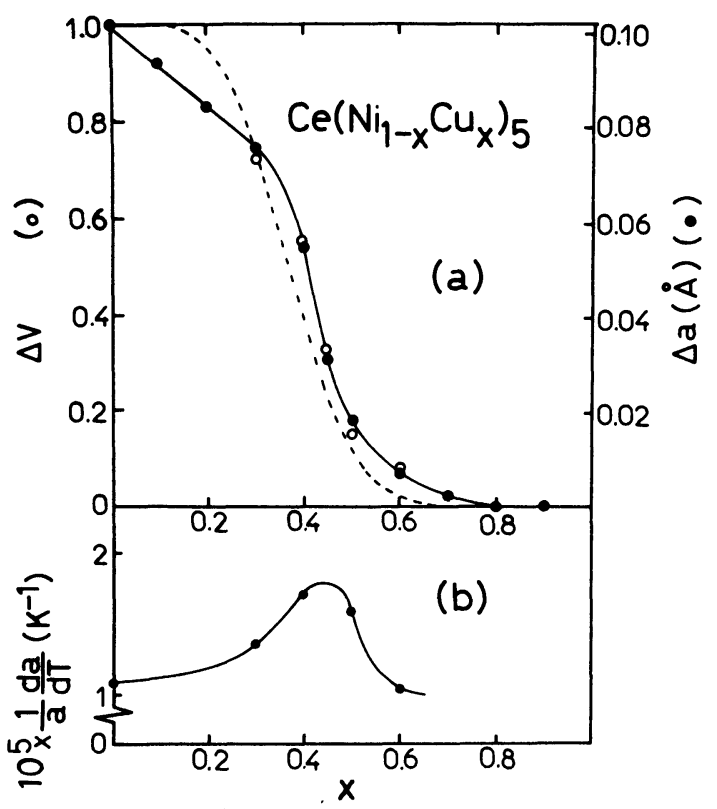

Fig. 2. $-a$ ) Deviation of the $a$ lattice parameter $\Delta a$ from $a^{3+}$ type variation (right hand scale, $\bullet$ ) and change of valence $\Delta V$ deduced from X-ray absorption experiments (left hand scale, $O$ ) in the $\mathrm{Ce}\left(\mathrm{Ni}_{1-x} \mathrm{Cu}_{x}\right)_{5}$ compounds versus the $\mathrm{Cu}$ concentration $x$. The dashed line represents the best fit in a Jaccarino-Walker [17] type model. b) Dilatation coefficient $\alpha_{a}$ between 150 and $300 \mathrm{~K}$ in the $\mathrm{Ce}\left(\mathrm{Ni}_{1-x} \mathrm{Cu}_{x}\right)_{5}$ compounds.

could be attributed to a preferential order of the $\mathrm{Cu}$ and $\mathrm{Ni}$ atoms on the $2 \mathrm{c}$ and $3 \mathrm{~g}$ sites. This would be detected by neutron diffraction experiments because of the difference in the $\mathrm{Cu}$ and $\mathrm{Ni}$ scattering lengths $\left(b_{\mathrm{Cu}}=0.76 \times 10^{-12} \mathrm{~cm}\right.$ and $\left.b_{\mathrm{Ni}}=1.03 \times 10^{-12} \mathrm{~cm}\right)$. Two alloys, with $\mathrm{Cu}$ concentrations on both sides of the large increase of the $a$ parameter were studied : $\mathrm{Ce}\left(\mathrm{Ni}_{0.7} \mathrm{Cu}_{0.3}\right)_{5}(x=0.3)$ and $\mathrm{Ce}\left(\mathrm{Ni}_{0.4} \mathrm{Cu}_{0.6}\right)_{5}(x=0.6)$. 
To enhance the probability of ordering, samples were annealed for 3 days at $700{ }^{\circ} \mathrm{C}$ and then cooled down to room temperature at a rate of $0.5 \% \mathrm{~min}$.

The occupancies $x_{2 \mathrm{c}}$ and $x_{3 \mathrm{~g}}$ of the 2 sites were obtained by refining the mean scattering lengths of the $\mathrm{M}$ atoms $b_{\mathrm{M}_{2 \mathrm{c}}}$ and $b_{\mathrm{M}_{3 \mathrm{~g}}}$ :

$$
b_{\mathrm{M}_{2 \mathrm{c}}}=x_{2 \mathrm{c}} b_{\mathrm{Cu}}+\left(1-x_{2 \mathrm{c}}\right) b_{\mathrm{Ni}}
$$

and

$$
b_{\mathrm{M}_{3 \mathrm{~g}}}=x_{3 \mathrm{~g}} b_{\mathrm{Cu}}+\left(1-x_{3 \mathrm{~g}}\right) b_{\mathrm{Ni}}
$$

$x_{2 \mathrm{c}}$ and $x_{3 \mathrm{~g}}$ are correlated to each other through the total $\mathrm{Cu}$ concentration $x$ by the relation

$$
2 x_{2 \mathrm{c}}+3 x_{3 \mathrm{~g}}=5 x \text {. }
$$

The best agreements were found for the following values :

$$
\begin{aligned}
& \text { for } x=0.3: \\
& x_{2 \mathrm{c}}=0.33 \pm 0.03 \text { implying } x_{3 \mathrm{~g}}=0.28 \pm 0.02,
\end{aligned}
$$

for $x=0.6$ :

$$
x_{2 \mathrm{c}}=0.65 \pm 0.03 \text { implying } x_{3 \mathrm{~g}}=0.57 \pm 0.02 \text {. }
$$

The calculated intensities $I_{c}$ are compared to the observed ones $I_{\mathrm{o}}$ on table $\mathrm{I}$. The reliability factors $R=\Sigma\left|I_{\mathrm{o}}-I_{\mathrm{c}}\right| / \Sigma I_{\mathrm{o}}$ are $3.2 \%$ for $x=0.3$ and $2.3 \%$ for $x=0.6$. For both compounds the $\mathrm{Cu}$ atoms are almost equally distributed on the 2 sites and the irregular variations of the lattice parameters cannot be associated with a preferential order of $\mathrm{Ni}$ and $\mathrm{Cu}$ atoms on the $2 \mathrm{c}$ and $3 \mathrm{~g}$ sites; the large increase of the $a$ parameter has to be attributed to an increase of the $\mathrm{Ce}$ atomic radius.

In order to check the interpretation of Buschow et al. [4] which involves a thermal change of valence of $\mathrm{Ce}$ in $\mathrm{CeNi}_{5}$, we have undertaken a study of the thermal variation of the lattice parameters of $\mathrm{CeNi}_{5}$ as well as those of $\mathrm{LaNi}_{5}$ and several $\mathrm{Ce}\left(\mathrm{Ni}_{1-x} \mathrm{Cu}_{x}\right)_{5}$ alloys,

\begin{tabular}{|c|c|c|c|c|c|c|c|c|}
\hline & \multicolumn{4}{|c|}{$\mathrm{Ce}\left(\mathrm{Ni}_{0.7} \mathrm{Cu}_{0.3}\right)_{5}$} & \multicolumn{4}{|c|}{$\mathrm{Ce}\left(\mathrm{Ni}_{0.4} \mathrm{Cu}_{0.6}\right)_{5}$} \\
\hline$h k l$ & $\theta$ & $I_{\mathrm{o}}$ & $I_{\mathrm{c}}$ & & $\theta$ & $I_{\mathrm{o}}$ & $I_{\mathrm{c}}$ & \\
\hline 100 & 10.9 & 300 & 310 & & 10.7 & 243 & 274 & \\
\hline 001 & 11.6 & 48 & 40 & & 11.5 & 30 & 34 & \\
\hline 101 & 16.0 & 30 & 36 & & 15.8 & 38 & 41 & \\
\hline 110 & 19.1 & 278 & 284 & & 18.7 & 275 & 280 & \\
\hline 200 & 22.2 & \multirow{2}{*}{2459} & 813 & \multirow{2}{*}{2355} & 21.7 & \multirow{2}{*}{2355} & 808 & \multirow{2}{*}{2300} \\
\hline 111 & 22.6 & & 1542 & & 22.2 & & 1492 & \\
\hline 002 & 23.7 & 3777 & 3801 & & 23.6 & 3629 & 3646 & \\
\hline 201 & 25.3 & 1569 & 1538 & & 24.8 & 1452 & 1422 & \\
\hline 102 & 26.4 & 249 & 280 & & 26.1 & 272 & 248 & \\
\hline 210 & 30.0 & 262 & 270 & & 29.3 & 215 & 241 & \\
\hline 112 & 31.2 & 217 & 246 & & 30.8 & 255 & 243 & \\
\hline 211 & 32.6 & \multirow{3}{*}{905} & 28 & \multirow{3}{*}{972} & 31.9 & \multirow{3}{*}{954} & 33 & \multirow{3}{*}{973} \\
\hline 202 & 33.5 & & 710 & & 33.0 & & 707 & \\
\hline 300 & 34.5 & & 235 & & 33.7 & & 233 & \\
\hline
\end{tabular}
around the drastic change of $a(x=0.3,0.4,0.5,0.6)$ for comparison. The measurements were obtained by $X$-ray diffraction with $\mathrm{Cr}$ radiation $(\lambda=2.28962 \AA)$

Table I. - Neutron diffraction experiment : comparison of the observed $\left(I_{0}\right)$ and calculated $\left(I_{\mathrm{c}}\right)$ intensities in $\mathrm{Ce}\left(\mathrm{Ni}_{0.7} \mathrm{Cu}_{0.3}\right)_{5}$ and $\mathrm{Ce}\left(\mathrm{Ni}_{0.4} \mathrm{Cu}_{0.6}\right)_{5}$ at room temperature.

$R=3.2 \%$

$R=2.3 \%$ 
from $4.2 \mathrm{~K}$ to room temperature. For all the compounds studied, the thermal dilatation along the c-axis is almost the same, the dilatation coefficient $\alpha_{c}=\Delta c / c \Delta T$ between 150 and $300 \mathrm{~K}$ being

$$
(1.08 \pm 0.05) \cdot 10^{-5} \mathrm{~K}^{-1} \text {. }
$$

The thermal variation of the $a$ parameter of $\mathrm{CeNi}_{5}$ is identical to that of $\mathrm{LaNi}_{5}$ (Fig. 3). There is therefore no change of the Ce valence in $\mathrm{CeNi}_{5}$ as the temperature increases from $4.2 \mathrm{~K}$ to room temperature. In the Ce pseudo-binary alloys the dilatation coefficient $\alpha_{a}=\Delta a / a \Delta T$ measured between 150 and $300 \mathrm{~K}$ shows a maximum around $x=0.4$ and 0.5 , these being the $\mathrm{Cu}$ concentrations for which the $a$ parameter varies drastically (Fig. $2 b$ ). These latter compounds might present a thermal change of the $\mathrm{Ce}$ valence.

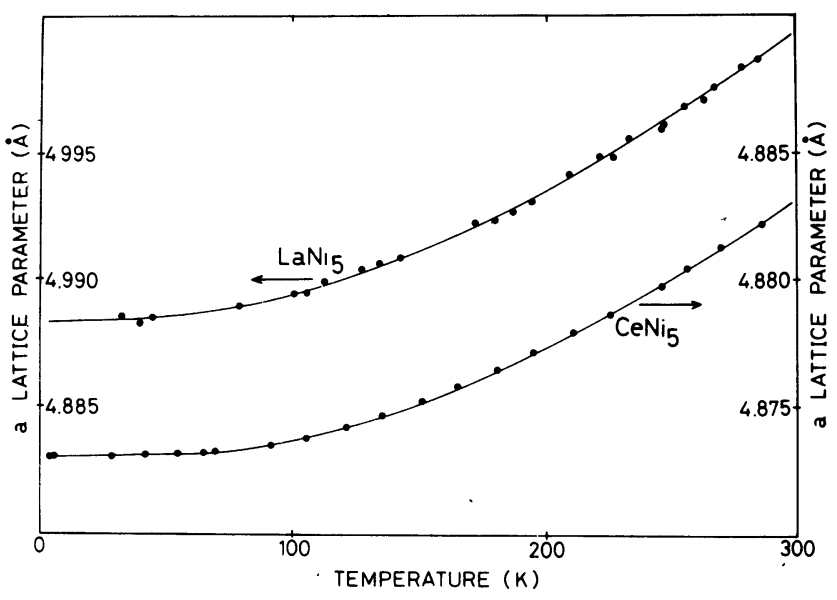

Fig. 3. - Thermal expansion of the $a$ parameter in $\mathrm{CeNi}_{5}$ (right hand scale) and $\mathrm{LaNi}_{5}$ (left hand scale).

3. Resistivity and magnetic properties. - The resistivity and the magnetic susceptibility of $\mathrm{CeNi}_{5}$ were studied on a single crystal along the a and $\mathbf{c}$ directions from $4.2 \mathrm{~K}$ to room temperature. The thermal dependence of the resistivity is monotonic but strongly anisotropic because of the uniaxial character of the crystallographic structure (Fig. 4). At very low temperatures it has a $B T^{2}$ dependence, the $B$ coefficient value being $7 \times 10^{-10} \Omega \mathrm{cm} \mathrm{K}^{-2}$ along $\mathrm{c}$ and $11 \times 10^{-10} \Omega \mathrm{cm} \mathrm{K} \mathrm{K}^{-2}$ along a, and the residual resistivities are 1.4 and $3.2 \times 10^{-6} \Omega \mathrm{cm}$ respectively.

The $\mathrm{CeNi}_{5}$ magnetization was measured at $4.2 \mathrm{~K}$ as a function of the magnetic field applied parallel to the c-axis (Fig. 5, insert) : its variation in fields larger than $50 \mathrm{kOe}$ is linear, the magnetization of the impurities being almost saturated. The value of the $\mathrm{CeNi}_{5}$ intrinsic susceptibility at $4.2 \mathrm{~K}$ is given by the slope of this straight line : $(30 \pm 2) \cdot 10^{-4}$ e.m.u./mole. The thermal dependence of the $\mathrm{CeNi}_{5}$ susceptibility was measured on a translation balance in order to get a more accurate variation (Fig. 5). However, at very low temperatures, a contribution due to the magnetic

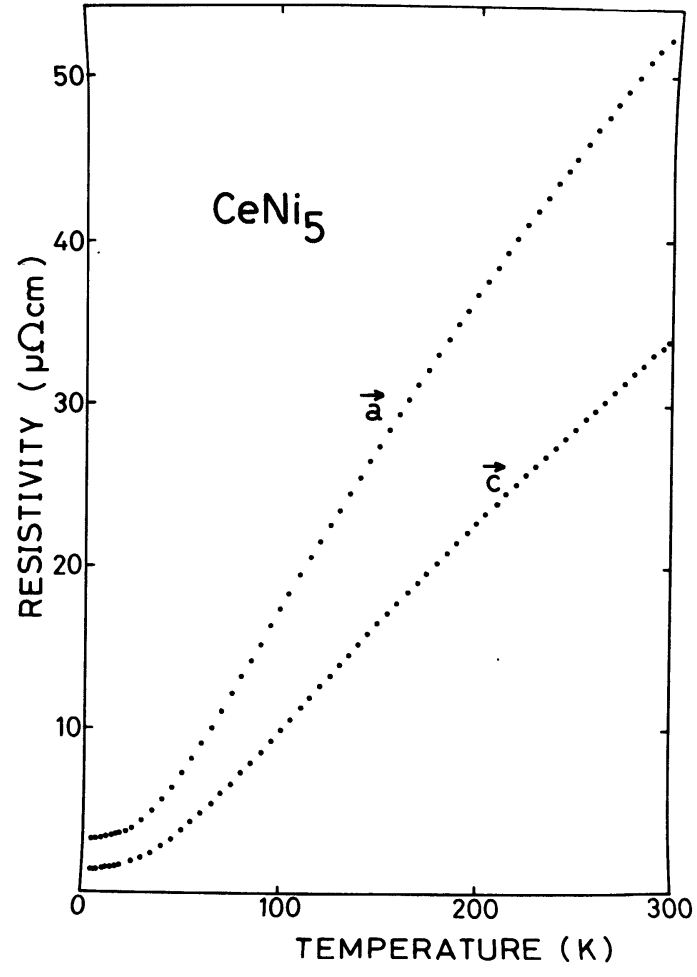

Fig. 4. - Thermal variation of the resistivity of $\mathrm{CeNi}_{5}$ measured along the $\mathbf{a}$ and $\mathbf{c}$ directions.

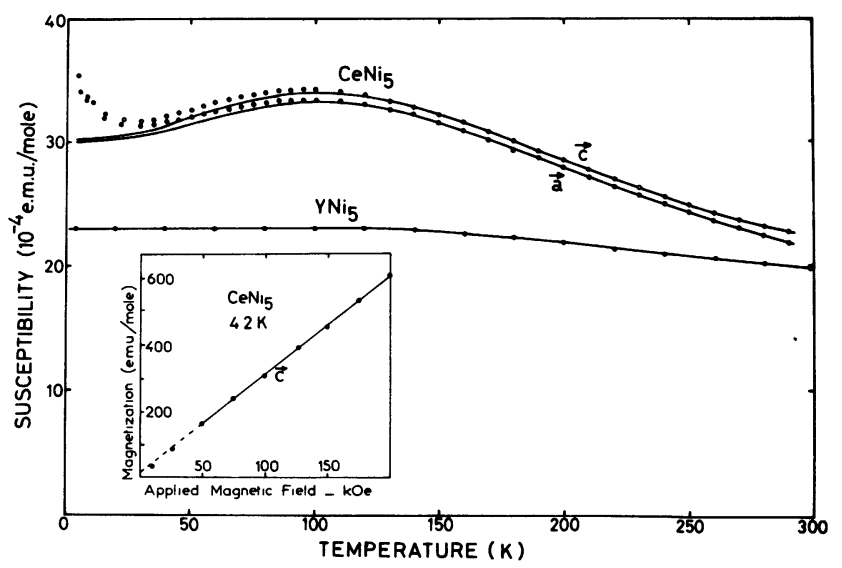

Fig. 5. - Thermal variations of the susceptibilities of $\mathrm{YNi}_{5}$ [9] and of $\mathrm{CeNi}_{5}$ measured along the $\mathrm{a}(\bullet)$ and $\mathrm{c}(\mathrm{O})$ directions. The continuous lines are the corrected intrinsic susceptibilities. Insert : field dependence of the $\mathrm{CeNi}_{5}$ magnetization at $4.2 \mathrm{~K}$ along the c direction.

impurities adds to the $\mathrm{CeNi}_{5}$ intrinsic susceptibility, leading especially to an increase of the measured susceptibility below $30 \mathrm{~K}$. The $\mathrm{CeNi}_{5}$ intrinsic susceptibility $\chi_{\text {int }}$ was then obtained by correcting this susceptibility measured on the translation balance $\chi_{\text {meas }}$ as described by Béal-Monod and Lawrence [6] for the $\mathrm{CeIn}_{3-x} \mathrm{Sn}_{x}$ compounds : $\chi_{\text {int }}=\chi_{\text {meas }}-C_{\text {imp }} / T$. Assuming that the thermal variation of $\chi_{\text {int }}$ follows between $4.2 \mathrm{~K}$ and $50 \mathrm{~K}$ the law [6] :

$$
\chi_{\text {int }}(T)=\chi(0)+A T^{2},
$$


the parameters $\chi(0), A$ and $C_{\text {imp }}$ were obtained from least square fits. Their values are

$$
\begin{gathered}
\chi(0)=29.8 \times 10^{-4} \text { e.m.u. } / \text { mole }, \\
A=7 \times 10^{-8} \text { e.m.u. } \mathrm{K}^{-2} / \mathrm{mole}
\end{gathered}
$$$$
\text { and } \quad C_{\text {imp }}=30 \times 10^{-4} \text { e.m.u. } \mathrm{K} / \mathrm{mole}
$$

for the field applied along a and

and

$$
\begin{aligned}
& \chi(0)=30.3 \times 10^{-4} \text { e.m.u. } / \mathrm{mole}, \\
& A=8 \times 10^{-8} \text { e.m.u. } \mathrm{K}^{-2} / \mathrm{mole} \\
& C_{\text {imp }}=25 \times 10^{-4} \text { e.m.u. } \mathrm{K} / \mathrm{mole}
\end{aligned}
$$

for the field applied along $\mathbf{c}$. The thermal dependence of the intrinsic susceptibilities along and $\mathbf{c}$ are compared in figure 5. The anisotropy is very weak. As previously determined by Buschow et al. [4] on a polycrystalline sample, the $\mathrm{CeNi}_{5}$ susceptibility shows a broad maximum around $100 \mathrm{~K}$, similar to those observed in $\mathrm{YCo}_{2}$ [7] or $\mathrm{LuCo}_{2}$ [8]. Moreover, at any temperature, the value of the $\mathrm{CeNi}_{5}$ susceptibility is close to those of $\mathrm{LaNi}_{5}$ and $\mathrm{YNi}_{5}$ (18 and $20 \times 10^{-4}$ e.m.u./mole respectively, at $300 \mathrm{~K}$ ). In figure 5, we have compared the thermal variation of $\mathrm{CeNi}_{5}$ to that of $\mathrm{YNi}_{5}$ which had been previously measured on a single crystal [9]. The physical properties of the Y-Ni and La-Ni compounds in which the $\mathrm{Ni}$ is close to the onset of magnetism are quite similar and very sensitive to the presence of impurities such as neighbouring phases. The $\mathrm{Y}$ compounds are easier to prepare as single crystals and, for this reason, their properties are better known [10].

The $\mathrm{Ce}\left(\mathrm{Ni}_{0.1} \mathrm{Cu}_{0.9}\right)_{5}$ susceptibility was measured on a polycrystalline sample. Its value at $20 \mathrm{~K}$ is $27 \times 10^{-3}$ e.m.u./mole which is one order of magnitude larger than in $\mathrm{CeNi}_{5}$. The reciprocal susceptibility (Fig. 6) follows a Curie-Weiss type law above $50 \mathrm{~K}$ with a slope corresponding to an effective moment of $2.56 \mu_{\mathrm{B}}$ which is very close to the expected value for $\mathrm{Ce}^{3+}\left(2.54 \mu_{\mathrm{B}}\right)$. Below $50 \mathrm{~K}$, the observed susceptibility

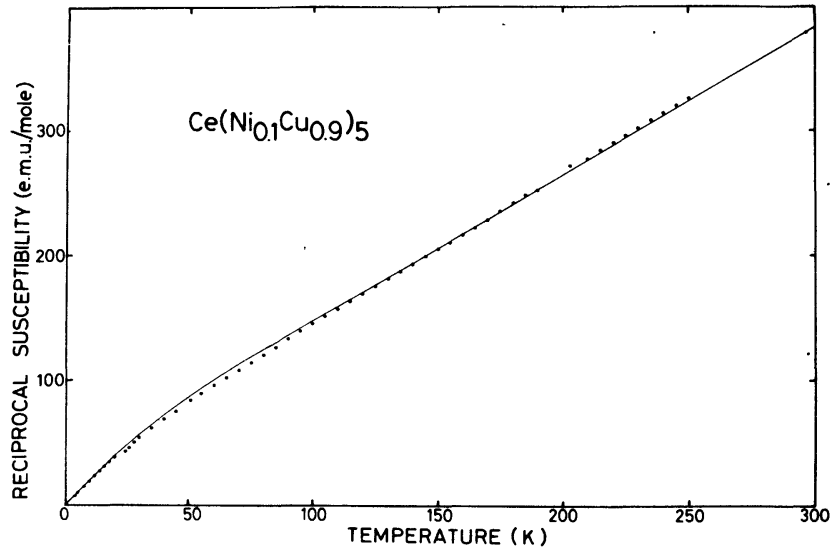

Fig. 6. - Thermal variation of the reciprocal susceptibility of $\mathrm{Ce}\left(\mathrm{Ni}_{0.1} \mathrm{Cu}_{0.9}\right)_{5}$ : - experimental point, - calculated curve for the parameters given in the text. is characteristic of the effects of a uniaxial crystal field on a $4 f$ ion, which tend to reduce the magnetic moment. A good agreement between the observed and the calculated variation is found for negligible magnetic exchange interactions between $\mathrm{Ce}$ atoms and with the following values of the crystal electric field parameters : $B_{2}^{0}=20 \mathrm{~K}, B_{4}^{0}=0.5 \mathrm{~K}$. There are no 6 th order terms associated with $\mathrm{Ce}^{3+}$. These values are in agreement with those deduced from various $\mathrm{RNi}_{5}$ compounds [11] by a scaling law $\left(B_{2}^{0}=15.5 \mathrm{~K}, B_{4}^{0}=-0.38 \mathrm{~K}\right)$. They lead to $\mathrm{a} \pm 1 / 2$ ground state for $\mathrm{Ce}$ in the com: pound studied.

4. X-ray absorption study. - The X-ray absorption measurements were performed on a (220) silicon monochromator, using the synchrotron radiation of D.C.I. at L.U.R.E. (Orsay, France). Intensities were measured before and after the sample using conventional ionization chambers. The powdered samples were held on a sticky tape. Several sample thicknesses were studied in order to test for the influence of beam harmonics, which turned out to be negligible. Figure 7 shows the structure of the Ce $\mathrm{L}_{\text {III }}$ absorption edges

$$
\left(\text { Ce } 2 \mathrm{p} 3 / 2 \rightarrow \mathrm{E}_{\mathrm{F}}, \Delta E \sim 5.7 \mathrm{keV}\right. \text { ) }
$$

in $\mathrm{Ce}\left(\mathrm{Ni}_{1-x} \mathrm{Cu}_{x}\right)_{5}$ for $\cdot x=0.8,0.6,0.5,0.4,0.3$ and 0 as well as in $\mathrm{CeCo}_{5}$ and the insulator $\mathrm{CeO}_{2}$. The difference between the absorption curve before the edge, and the mean absorption averaged over the EXAFS oscillations after the edge is normalized to 1 . As shown in section 2, the $\mathrm{Ce}$ ion in $\mathrm{Ce}\left(\mathrm{Ni}_{0.2} \mathrm{Cu}_{0.8}\right)_{5}$ is in the normal trivalent state. The $\mathrm{L}_{\mathrm{III}}$ edge of $\mathrm{Ce}$ in this compound presents a strong peak, which is a few electron volts wide. This peak is in fact a general feature for rare earth atoms in a trivalent state and is largely due to transitions into empty $5 \mathrm{~d}$ states. A double absorption edge is observed in $\mathrm{CeO}_{2}$ which is a good insulator. To preserve electro-neutrality, the cerium must be in the $\mathrm{Ce}^{4+}$ state in this ionic oxide. Since our sample was checked to be perfectly pure by magnetic and crystallographic analysis, this double peaked edge is characteristic of $\mathrm{Ce}^{4+}$ and must be related to two different final states, the additional one corresponding to a change in the $4 f$ occupancy [12]. The $\mathrm{CeCo}_{5}$ and $\mathrm{CeNi}_{5}$ spectra are similar to that of $\mathrm{CeO}_{2}$. $\mathrm{Ce}$ is therefore very close to a tetravalent state in these two intermetallic compounds. Their absorption edges lie at lower energy than that of $\mathrm{CeO}_{2}$ because their Fermi energies lie below the $5 \mathrm{~d}$ ionic level. For $\mathrm{Cu}$ concentrations ranging from 0.8 to 0.3 the shape of the absorption edge changes gradually from that characteristic of the trivalent state (A) to that characteristic of the almost tetravalent state (B). Analysis of these spectra by fractional superposition of $(A)$ and (B) spectra gives the valence change $\Delta V$ as a function of the concentration $x$. This variation is compared to the $a$ variation in figure $2 a$. The two curves are quite superposed. The anomalous variation of the $a$ lattice parameter is thus due to a change of the Ce valence 

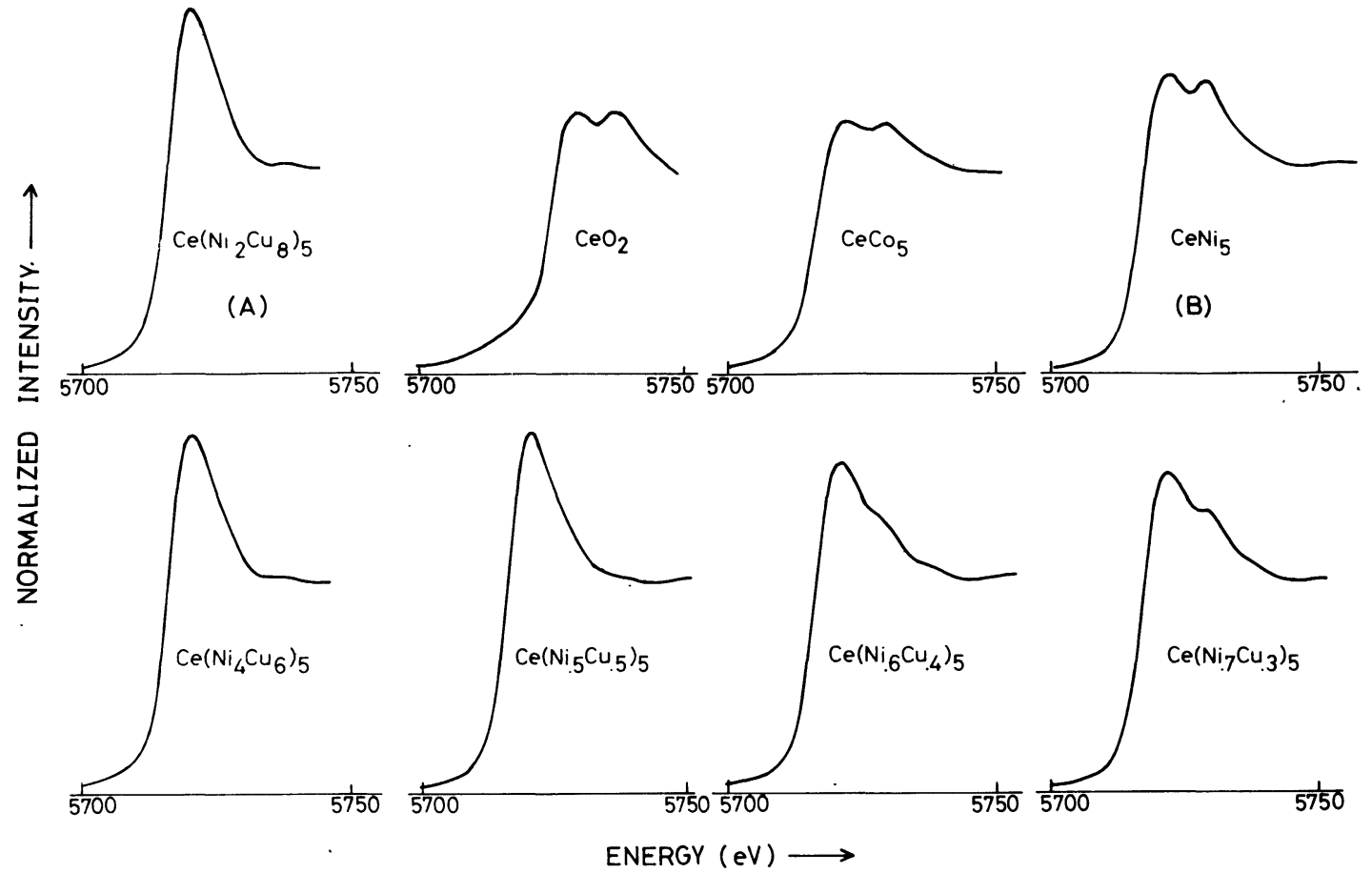

Fig. 7. - $\mathrm{L}_{\mathrm{III}}$ absorption edges for $\mathrm{Ce}$ in $\mathrm{CeNi}_{5}, \mathrm{CeCo}_{5}, \mathrm{CeO}_{2}$ and various $\mathrm{Ce}\left(\mathrm{Ni}_{1-x} \mathrm{Cu}_{x}\right)_{5}$ alloys at room temperature.

from almost $4+$ to $3+$ with increasing $\mathrm{Cu}$ concentration.

5. Discussion. - The two $\mathrm{CeNi}_{5}$ and $\mathrm{CeCo}_{5}$ compounds exhibit the same $\mathrm{L}_{\text {III }} \mathrm{X}$-ray absorption edges as in $\mathrm{CeO}_{2}$, implying that in these two compounds $\mathrm{Ce}$ is very close to a tetravalent state. This conclusion, which is different from that of Bauchspiess et al. [5] is based on a different interpretation of the double peaked edge in $\mathrm{CeO}_{2}$. In this ionic insulator, an intermediate valence of 3.3 of $\mathrm{Ce}$ does not preserve electroneutrality, while the double peak observed can be due to two different final states after the X-ray absorption process [12]. Moreover, our conclusion is consistent with the other experimental results presented in this paper.

The $a$ lattice parameter variation inside the series $\mathrm{RCu}_{5}, \mathrm{RCo}_{5}$ and $\mathrm{RNi}_{5}[1]$ is reported in figure 8. The lattice anomaly is smaller in $\mathrm{CeNi}_{5}(0.105 \AA)$ than in $\mathrm{CeCo}_{5}(0.145 \AA)$. As this difference does not result from different valence states, it can be explained by slight changes in their stoichiometries. $\mathrm{RNi}_{5}$ compounds are generally stoichiometric while for the $\mathrm{RCo}_{5}$ compounds with small radii rare earths, an increase of Co concentration stabilizes the phase : for instance the composition of the alloy with $\mathrm{Er}$ reaches $\mathrm{ErCo}_{6}[13,14]$. The excess of $\mathrm{Co}$ is caused by Co dumb-bells parallel to c replacing rare earth atoms : this involves an increase of the $c$ parameter and simultaneously a decrease of the $a$ parameter. The thin line on figure 8 represents the $a$ parameter variation in $\mathrm{RCo}_{5}$ compounds without any change in stoichiometry. It was obtained from the $a$ parameter variation in the $\mathrm{RNi}_{5}$

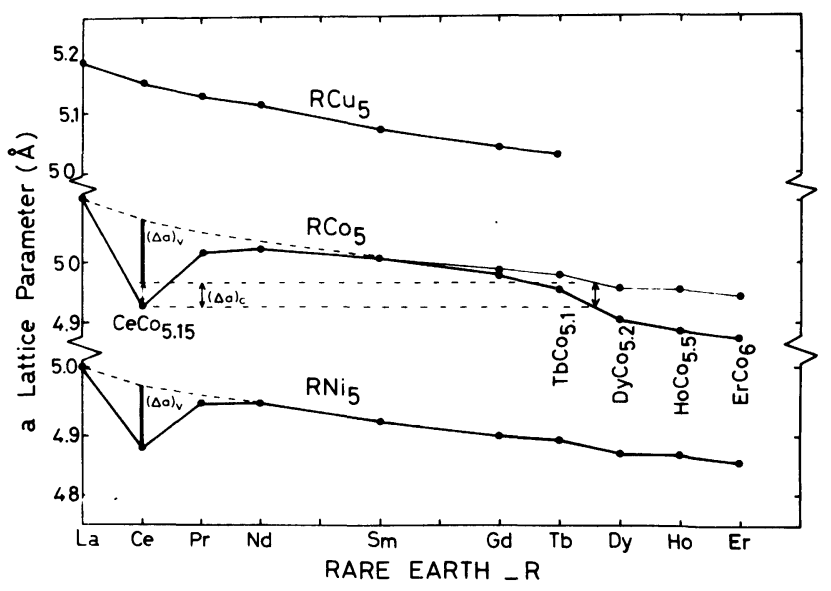

Fig. 8. - $a$ lattice parameters in the series $\mathrm{RCu}_{5}, \mathrm{RCo}_{5}$ and $\mathrm{RNi}_{5}$. The dashed line corresponds to the $\mathrm{RCu}_{5}$ type variation. The thin line is parallel to the $\mathrm{RNi}_{5}$ variation.

compounds. The parameter anomaly in $\mathrm{CeCo}_{5}$ results from combined effects : the anomaly $(\Delta a)_{V}(=0.105 \AA)$ is due to the Ce volume reduction in the tetravalent state; it involves an increase of the Co concentration and then an additional decrease $(\Delta a)_{c}(=0.040 \AA)$ of the $a$ parameter. The composition of the cerium-cobalt compound thus deduced is $\mathrm{CeCo}_{5.15}$. According to the relation $a=\sqrt{3}\left(r_{\mathrm{Ce}}+r_{\mathrm{M}}\right)$, the relative variation of the Ce atomic radius $\Delta r_{\mathrm{Ce}} / r_{\mathrm{Ce}}$ associated with the $a$ parameter reduction due to the change of valence $(\Delta a)_{V}$ would be $5 \%$. In fact, this relative variation reaches $9 \%$ in Ce metal [15], or in a Ce ion [16]. This difference can be attributed to the modification of the band structure. In $\mathrm{CeCo}_{5}$ or $\mathrm{CeNi}_{5}$, due to the almost 
tetravalent state of cerium, more electrons are transferred to the $3 \mathrm{~d}$ band, and the reduction of the Ce-M distance (that is the $a$ reduction) is less important due to hybridization effects. In conclusion, in order to analyse a valence change from the variation of the lattice parameters, it is necessary to take account, not only of the volume dependence of the ions, but also of the stoichiometry changes which generally occur and of the modification of the band structure, in the case of intermetallic compounds.

The valence state of $\mathrm{Ce}$ in the various compounds studied depends in fact on the possibility of transferring $5 \mathrm{~d}$ electrons towards the $3 \mathrm{~d}$ band. In $\mathrm{Co}$ and $\mathrm{Ni}$, the $3 \mathrm{~d}$ band is unfilled; because of the difference in electronegativity between these elements and the rare earths, $5 \mathrm{~d}$ electrons are transferred to the $3 \mathrm{~d}$ band, lowering the Fermi level $\mathrm{E}_{\mathrm{F}}$ of the compound compared to the Fermi level of the rare earth metal. If the $4 \mathrm{f}^{1}$ level is higher than $\mathrm{E}_{\mathrm{F}}$, the Ce becomes tetravalent. With $\mathrm{Cu}$, the $3 \mathrm{~d}$ band is filled up and no transfer is then possible : the Ce remains trivalent.

The change from the almost $4+$ to the $3+$ valence state is observed in the $\mathrm{Ce}\left(\mathrm{Ni}_{1-x} \mathrm{Cu}_{x}\right)_{5}$ compounds with increasing concentration $x$ (Fig. 2a). The Ce valence state decreases linearly with $x$ up to $x=0.3$ and more rapidly for higher copper concentrations. A drastic change of valence related to a critical number of near neighbour $\mathrm{Cu}$ atoms cannot account for such a dependence : as a matter of fact, the best fit to the experimental variation (Fig. $2 a$, dashed line) calculated within a statistical' model of the Jaccarino-Walker type [17] corresponds to a critical number of $7 \mathrm{Cu}$ atoms among the $18 \mathrm{Cu}$ or $\mathrm{Ni}$ atoms neighbouring one $\mathrm{Ce}$ atom. The agreement is very poor for the low copper concentrations. In fact, the experimental curve shows two processes : the regular decrease of the valence as $x$ increases from 0 to $x=0.3$ could be interpreted by the progressive filling of a $4 f^{1}$ virtual bound state. In $\mathrm{CeNi}_{5}$ this bound state is almost empty. The filling occurs as the Fermi level rises because of the decreased transfer of electrons towards the $3 \mathrm{~d}$ band with increasing $x$. For concentrations above $x=0.3$, the existence of a critical concentration and of associated neighbouring effects could account for the drastic decrease of the Ce valence. In fact, theoretical calculations in the Anderson model [18] show the existence of such a critical value of $x$.

Moreover, it can be noted that the thermal dilatation coefficient $\alpha_{a}$ presents a maximum (Fig. $2 b$ ) for $x$ values corresponding to the steepest part of the curve $\Delta V(x)$ $(0.4<x<0.5)$. However, for these compounds, the thermal change of valence between 150 and $300 \mathrm{~K}$, deduced from the $\Delta V$ variation versus $\Delta a$ (Fig. 2a) is $\Delta V=0.05$ only.

The magnetic properties can also be well explained taking into account the valence states determined above. It has been shown that the thermal variation of the susceptibility of $\mathrm{Ce}\left(\mathrm{Ni}_{0.1} \mathrm{Cu}_{0.9}\right)_{5}$ is characteristic of the effects of a uniaxial crystalline field on the $\mathrm{Ce}^{3+}$ ion. In such a case, the susceptibility is anisotropic, as are those of the other $\mathrm{RNi}_{5}$ compounds [11] $\left(\mathrm{R} \neq \mathrm{Ce}\right.$ or $\mathrm{Gd}$ ). In $\mathrm{CeNi}_{5}$, the susceptibility exhibits a negligible anisotropy, which cannot originate from 4f electrons. Moreover, its value is comparable to those of $\mathrm{LaNi}_{5}$ and $\mathrm{YNi}_{5}$. In fact, $\mathrm{CeNi}_{5}$, like $\mathrm{LaNi}_{5}$ and $\mathrm{YNi}_{5}$, is an enhanced Pauli paramagnet close to the Stoner criterion, as confirmed by the $B T^{2}$ low temperature dependence of its resistivity. In the (Y-Ni) system, a resurgence of ferromagnetism is observed for the compounds with a $\mathrm{Y}$ concentration between $\mathrm{YNi}_{5}$ and $\mathrm{YNi}_{2}$. This phenomenon can be explained by an increase of the $3 d-4 d$ hybridization as the $Y$ concentration increases, involving an increase of the density of states at the Fermi level [19]. In addition, the greater number of conduction electrons in $\mathrm{Ce}$, corresponding to its almost tetravalent state, implies a greater $3 d-5 d$ hybridization in $\mathrm{CeNi}_{5}$ than in $\mathrm{YNi}_{5}$. Therefore the density of states at the Fermi level and hence the susceptibility are larger in $\mathrm{CeNi}_{5}$ than in $\mathrm{YNi}_{5}$. The band structures of the two compounds deduced from the calculations of Cyrot and Lavagna [20] are schematically drawn on figure 9. They

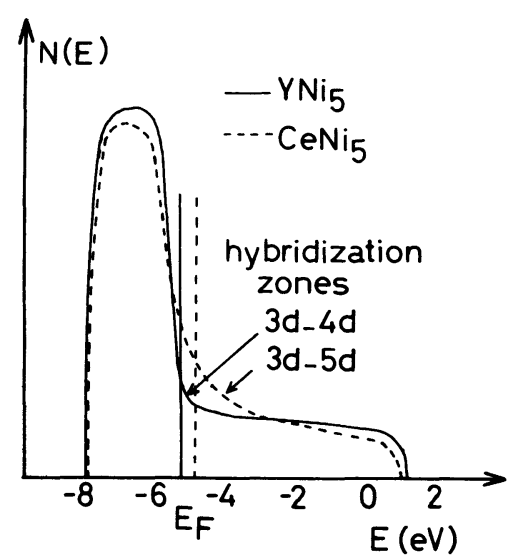

Fig. 9. - Scheme of the density of state curves in $\mathrm{YNi}_{5}(-)$ and $\mathrm{CeNi}_{5}(---)$

allow an explanation of the thermal variation of the susceptibilities. As shown by Wohlfarth and Rhodes [21] for enhanced paramagnetism, and by BéalMonod and Lawrence [6] in the paramagnon picture, the maximum observed in $\mathrm{CeNi}_{5}$ could result from the Fermi level lying in a zone of the density of states with a positive curvature. At low temperature $(T<50 \mathrm{~K})$ the $\mathrm{CeNi}_{5}$ intrinsic susceptibility follows the law characteristic of a nearly magnetic fermion system [6] : $\chi(T)=\chi(0)+A T^{2}$, where $A$ is positive. In $\mathrm{YNi}_{5}$, the Fermi level does not lie in a zone with a positive strong curvature. Consequently the susceptibility decreases slightly with increasing temperature. A polarized neutron study [22] has actually confirmed that the dominant part of the $\mathrm{CeNi}_{5}$ susceptibility originates from a $3 \mathrm{~d}$ magnetism associated with the $\mathrm{Ni}$ atoms, as in $\mathrm{YNi}_{5}$ [23]. 
Acknowledgmènts. - We are pleased to acknowledge stimulating discussions with $\mathrm{C}$. Lacroix from our Laboratory and with G. Krill from L.M.S.E.S. : (Strasbourg, France).

\section{References}

[1] Wernick, J. H., Geller, S., Acta Crystallogr. 12 (1959) 662.

[2] Velge, W. A. J., Buschow, K.·H. J., J. Appl. Phys. 39 (1968) 1717.

[3] Lemaire, R., Schweizer, J., J. Physique 28 (1967) 216.

[4] Bushcow, K. H. J., Brouha, M., Van DaAl, H. J., Miedema, $\mathrm{H}$. $\mathrm{R}$., in Valence instabilities and related narrow bands phenomena, Conf. of Rochester, edited by R. D. Parks (Plenum Press, New York) 1977, p. 125.

[5] Bauchspiess, K. R., BoKsch, W., Holland-Moritz, E., Launois, H., PotT, R., Wohlleben, D., in Valence fluctuations in solids, edited by L. M. Falicov, W. Hanke, M. P. Maple (North-Holland Publishing Company) 1981, p. 417.

[6] Beal-Monod, M. T., Lawrence, J. M., Phys. Rev. B 21 (1980) 5400.

[7] LemaIRe, R., Cobalt 33 (1966) 201.

[8] Bloch, D., Chaisse, F., Givord, F., Vorron, J., Burzo, E., J. Phys. C 32 (1971) 659.

[9] Gignoux, D., Givord, D., Del Moral, A., Solid State Commun. 19 (1976) 891.

[10] Gignoux, D., Lemaire, R., Molho, P., Tasset, F., J. Appl. Phys. 52 (1981) 2087.

[11] Nart SaAda, A., Thèse de Doctorat d'Etat, Grenoble University (1980).
[12] Krill, G., Kappler, J. P., Meyer, A., Abadli, L., Ravet, M. F., J. Phys. F : Metal Phys. 11 (1981) 1713.

[13] Buschow, K. H. J., Z. Metallkd. 57 (1966) 728.

[14] Schweizer, J., TAsSeT, F., J. Less-Common Met. 18 (1969) 245.

[15] Beaudry, B. J., Gschneidner Jr., K. A., in Handbook of the physics and chemistry of rare earths, edited by $\mathbf{K}$. A. Gschneidner, Jr. and L. Eyring (North-Holland) Vol. 1, 1978, p. 173.

[16] Iandelli, A., Palenzona, in Handbook of the physics and chemistry of rare earths, edited by K. A. Gschneidner Jr. and L. Eyring (North-Holland) Vol. 2, 1979, p. 1.

[17] Jaccarino, V., WALker, L. R., Phys. Rev. Lett. 15 (1965) 258.

[18] LaCroix, C., to be published in J. Phys. F : Metal Phys.

[19] Gignoux, D., Givord, D., Laforest, J., Lemaire, R., Molho, P., Physics of transition metals, Leeds, Great Britain, 1980.

[20] Cyrot, M., Lavagna, M., J. Physique 40 (1979) 763.

[21] Wohlfarth, E. P., Rhodes, P., Philos. Mag. 7 (1962) 1817.

[22] Gignoux, D., Givord, F., Lemaire, R., TAsset, F., in The rare earths in modern science and technology, edited by G. J. McCarthy and J. J. Rhyne (Plenum Press) Vol. 2, to be published. Proc. of the 15th Rare Earth Research Conference, June 1981.

[23] Gignoux, D., Givord, D., Lemaire, R., Nait SaAda, A., Del Moral, A., J. Mag. Magn. Mat. 23 (1981) 274. 